\title{
Occupational hand dermatoses of hairdressers in Tainan City
}

\author{
Yueliang Leon Guo, Bour-Jr Wang, J Yu-Yun Lee, Shu-Yuan Chou
}

\begin{abstract}
Objectives-To determine the prevalence, clinical features, and patterns of hand dermatosis in hairdressers in Tainan, Taiwan, and to examine the associations between patterns of dermatosis and risk factors such as job description, work exposure, and sensitisation to common allergens.

Methods-Interviews, examinations, and patch tests of the hairdressers from nine hairdressing stores randomly selected from Tainan City. Patch test agents included 41 substances with common allergens, shampoo preservatives, hair dyes, permanent waving and bleaching agents.
\end{abstract}

Results-98 hairdressers finished the examination, $83 \%$ of them had occupational dermatosis and $32 \%$ had scissor induced scars or wounds. Most of the dermatoses belonged to either dry metacarpophalangeal dermatitis or eczema of the fingers. $44 \%$ of the hairdressers showed positive skin reaction to one or more patch test agents. The patch test results were different from previous reports in that the most common allergens were nickel, thimerosal, Captan, Kathon CG, and fragrance mix, and that the sensitivity to hair dye and permanent wave ingredients were low. The dry metacarpophalangeal dermatitis was associated with exposure to shampoo, and the eczema of the fingers with skin sensitivity to patch test agents.

Conclusion-Hairdressers in Tainan City had a high prevalence of dermatoses including traumatic wounds, and allergic and irritant contact dermatitis. The rates of sensitivity to some of the common sensitising agents were different from previous reports.

(Occup Environ Med 1994;51:689-692)

Keywords: occupational dermatitis, hairdressers, patch tests

Occupational hand dermatosis among hairdressers has been recognised as a significant health concern. ${ }^{1-3}$ The dominant occupational skin disorder for hairdressers is contact dermatitis of both irritant and allergic types. Irritant dermatitis is mostly attributed to wet work and exposure to shampoos. Nickel, formaldehyde, fragrance, rubber additives, ammonium thioglycolate, and p-phenylenediamine and its related agents have been identified as the common allergens in this occupation. ${ }^{45}$ Cronin reported two main patterns of hand dermatitis in hairdressers: the dry irritant metacarpophalangeal (MP) joint pattern, and eczema of the fingers. ${ }^{6}$ The association between these dermatoses and sensitivity to common allergens is not understood, although it has been suggested that the MP type was likely to be associated with wet work and contact with shampoo. ${ }^{2}$

In Taiwan, the hairdressers usually work longer hours than in western countries. One would expect hand dermatosis to be a significant health problem among Taiwan's hairdressers, but the actual statistics are lacking. In this study, we examined the prevalence, clinical features, and patterns of hand dermatoses in hairdressers in Tainan city, Taiwan. Associations between patterns of dermatosis and risk factors such as job description, work exposure, and sensitisation to common allergens were investigated.

\section{Subjects and methods}

We visited nine randomly selected hairdressing shops with at least 10 workers in Tainan City. After obtaining their informed consent, the hairdressers were interviewed for their current job description, work exposure, work history, medical history, and factors associated with skin problems-for example, pierced ears. Skin examination was performed by a dermatologist and photographs of hands were taken. Severity of dermatological signs were graded according to the following criteria: mild if there was any presence of thickening or scaling of the skin; moderate if there was erythema, itching, or hyperpigmentation associated with thickening: and severe if there was oedema, vesicles, fissures, or notable erythema. The photographs were later reviewed blind for skin manifestations and patterns of dermatitis. The dermatitis was categorised into two types: dry irritant dermatitis of the MP joint areas with lichenification or scaling (MP type); and eczematous dermatitis especially that involved the fingers, but spared the MP areas. Most of the MP type dermatitis involved the dorsal more than the palmar surface.

Allergens from the standard tray and hairdressers tray including shampoo preservatives, hair dyes, and their related agents, and permanent waving and bleaching agents (Chemotechnique Diagnostic AB, Sweden) 
were used for patch testing. The test agents were applied to Finn chambers (Epitest, Helsinki, Finland) which were fixed to the upper back with Scanpor tape and secured by $3 \mathrm{M}$ tape. The patches were removed after $48 \mathrm{~h}$ and the sites were examined for evidence of a reaction at 48 and $72 \mathrm{~h}$ after initial application. ${ }^{7}$ The reading at $72 \mathrm{~h}$ was considered positive if the reaction was equal to or

Table 1 Work description of the 98 hairdressers

\begin{tabular}{|c|c|c|}
\hline & Stylists & Apprentices \\
\hline $\begin{array}{l}\text { Work duration (h/ } \\
\text { Full time } \\
\text { Part time }\end{array}$ & $\begin{array}{l}73.67(1.26)(n=33) \\
11.50(0.50)(n=3)\end{array}$ & $\begin{array}{c}73.56(1.37)(n=57) \\
8.80(3.35)(n=5)\end{array}$ \\
\hline $\begin{array}{l}\text { Full time workers } \\
\text { Shampooing } \\
\text { Waving } \\
\text { Dyeing } \\
\text { Cutting } \\
\text { Cosmetic work } \\
\text { Blow drying }\end{array}$ & $\begin{array}{r}0.01(0.01)(\mathrm{n}=33) \\
6.86(1.91) \\
0.14(0.07) \\
8.85(1.66) \\
0.15(0.15) \\
21.93(2.47)\end{array}$ & $\begin{array}{l}15.07(1 \cdot 10)(\mathrm{n}=57) \\
12.56(3.26) \\
0.43(0 \cdot 11) \\
0 \\
0 \\
7.61(1.32)\end{array}$ \\
\hline $\begin{array}{l}\text { Reported time we } \\
\text { Shampooing } \\
\text { Waving } \\
\text { Dyeing } \\
\text { Cutting } \\
\text { Cosmetic work } \\
\text { Blow drying }\end{array}$ & $\begin{array}{l}0 \\
2 \cdot 9(1 \cdot 7) \\
17 \cdot 1(6 \cdot 5) \\
0 \\
0 \\
0\end{array}$ & $\begin{array}{l}3.7(1.9) \\
1.6(1.6) \\
30.6(5.9) \\
\text { NA } \\
\text { NA } \\
0\end{array}$ \\
\hline
\end{tabular}

Results are expressed as means (SEM).

$\mathrm{NA}=$ not applicable because apprentices were not involved in dyeing or cutting.

Table 2 Severity of dermatitis and presence of scars in stylists and apprentices

\begin{tabular}{lccc}
\hline & $\begin{array}{c}\text { Apprentices } \\
(n(\%))\end{array}$ & $\begin{array}{l}\text { Stylists } \\
(n(\%))\end{array}$ & $\begin{array}{l}\text { Total } \\
(n(\%))\end{array}$ \\
\hline $\begin{array}{l}\text { Dermatitis }{ }^{\star}: \\
\text { Absent }\end{array}$ & $1(1 \cdot 6)$ & $15(41 \cdot 7)$ & $16(16 \cdot 3)$ \\
Mild & $18(29 \cdot 0)$ & $11(30 \cdot 6)$ & $29(29 \cdot 6)$ \\
$\begin{array}{l}\text { Moderate } \\
\text { Severe }\end{array}$ & $42(67 \cdot 7)$ & $9(25 \cdot 0)$ & $51(52 \cdot 0)$ \\
$1(1 \cdot 6)$ & $1(2 \cdot 8)$ & $2(2 \cdot 0)$ \\
Web scarst: & & & \\
$(-)$ & $60(96 \cdot 8)$ & $7(19 \cdot 4)$ & $67(68 \cdot 4)$ \\
$(+)$ & $2(3 \cdot 2)$ & $29(80 \cdot 6)$ & $31(31 \cdot 6)$ \\
Total & 62 & 36 & 98 \\
\hline
\end{tabular}

$\star P<0.0001$ apprentices had more severe dermatitis, by $\chi^{2}$ test. $t P<0.0001$ stylists had more scars in the web between the index and middle fingers, by $\chi^{2}$ test.

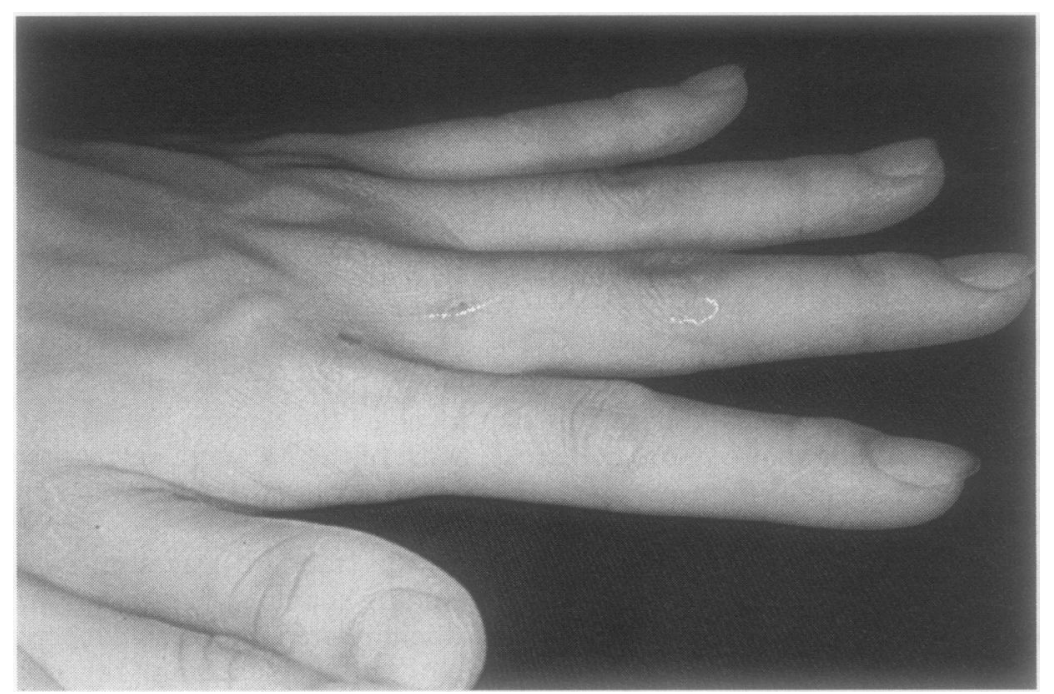

Figure 1 Scissor induced wounds. stronger than a palpable erythema. The data were analysed by descriptive statistics, analysis of variance, and $\chi^{2}$ test with the SAS package.

\section{Results}

There were 108 hairdressers enrolled in this study. Among them, 10 did not return for examination either at 48 or $72 \mathrm{~h}$ and were excluded from the final analysis. This resulted in 98 subjects in the complete data analysis. The 98 subjects consisted of 15 men and 83 women. The median age was 19 years, median duration of work was 24 months, and mean duration of work was 39 months. Among the 98 subjects, 36 were stylists and 62 were apprentices. The mean (range) duration for an apprentice to become a stylist was 27 (9-64) months. Table 1 shows their work descriptions. Full time hairdressers worked long hours, on average $73.7 \mathrm{~h}$ for stylists and $74.4 \mathrm{~h}$ for apprentices per week. The main duties of the stylists were cutting, blow drying, and waving whereas the apprentices do shampooing, waving, blow drying, and dyeing. Hairdressers used gloves infrequently.

Hand dermatitis was seen in 82 subjects. The duration of the skin lesions persisted for $>1$ year in $60 \%$ and $<1$ year in $40 \%$ of the cases. Dermatitis seemed to be more severe in the apprentices than in the stylists (table 2). A unique manifestation was trauma induced wounds or scars over the web between the index and middle fingers of the non-dominant hand (fig 1) due to cuts from scissors during hair cutting (fig 2). The stylists had significantly more web scars than did the apprentices (table 2).

Table 3 shows the results of patch tests for the 98 subjects. None of the 98 subjects had skin sensitivity to hydrogen peroxide, hydroquinone, chloroacetamide, 2-bromo-2nitropropane-1,3-diol, 4-chloro-3-cresol, imidazolidinyl urea, quaternium 15, zinc pyrithione, lanolin, benzocaine, $p$-aminobenzoic acid, p-tert-butylphenol formaldehyde resin, and toluenesulphonamide formaldehyde resin. Forty three hairdressers reacted to at least one allergen tested, and 27 reacted to at least one non-nickel allergen. The prevalence of positive skin tests was not different between stylists and apprentices. Previously pierced ears seemed to be a major risk factor for developing nickel sensitivity (table 4).

Among the 82 hairdressers with dermatitis, cleaning agents were reported by 51 individuals as the aggravating factor for their symptoms. Fifty seven of the 82 individuals with dermatitis reported worst symptoms during the winter. Seventy seven of the 98 subjects thought that the skin problems were related to work exposure. Shampooing (42/62) was considered by most apprentices to be the cause of skin diseases, then perm (10/62), hot water burns $(3 / 62)$, and a scissor cut $(1 / 62)$. Scissor cuts were considered to be the most important cause of skin problems by $12 / 36$ 
stylists, then shampooing (7/36), and perm (3/36).

Among the 82 subjects with hand dermatitis, MP type eruption was identified in 56 subjects and eczema of the fingers in 20 . No clear pattern was identified in the remaining six cases. Apprentices had more dermatitis of both MP type and eczema of the fingers than

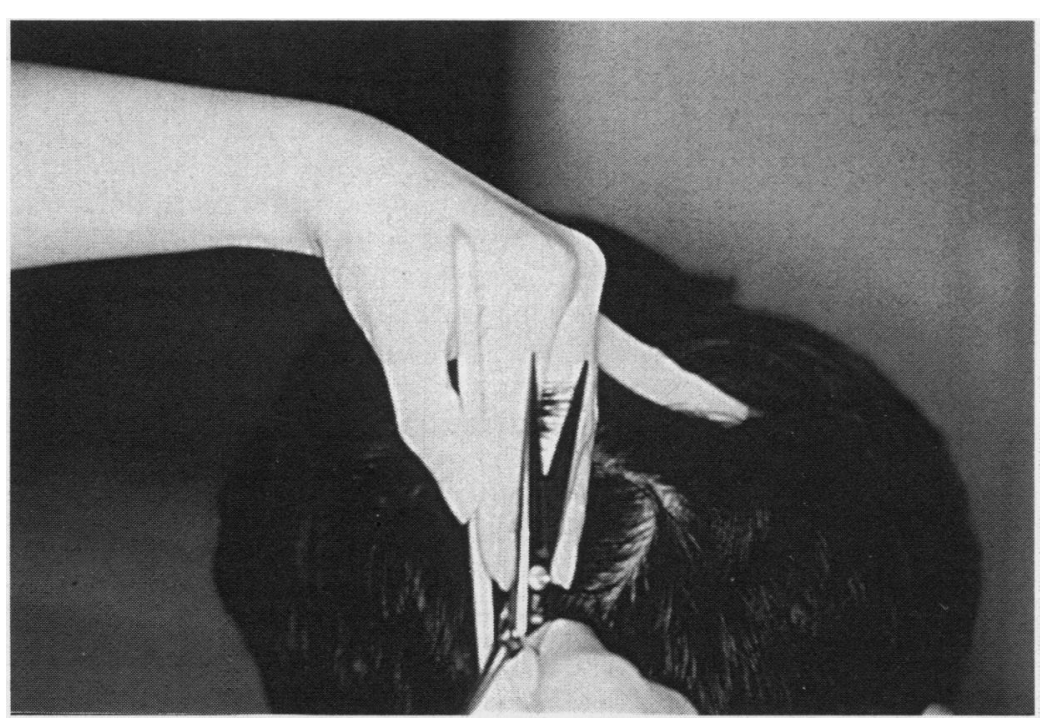

Figure 2 Position of the non-dominant hand during hair cutting.

Table 3 Patch test results $(n=98)$

\begin{tabular}{lclc}
\hline & $\begin{array}{l}\text { Concentration } \\
(\% w / w)\end{array}$ & Solvent & $\begin{array}{c}\text { Positive } \\
\text { reactions }\end{array}$ \\
\hline 4-Phenylenediamine dihydrochloride & $0 \cdot 5$ & pet & 3 \\
p-Toluenediamine sulphate & $1 \cdot 0$ & pet & 0 \\
p-Aminodiphenylamine & $1 \cdot 0$ & pet & 0 \\
Resorcinol & $1 \cdot 0$ & pet & 1 \\
3-Aminophenol & $1 \cdot 0$ & pet & 2 \\
4-Aminophenol & $1 \cdot 0$ & pet & 0 \\
Ammonium thioglycolate & $2 \cdot 5$ & aq & 2 \\
Glyceryl monothioglycolate & $1 \cdot 0$ & aq & 2 \\
Ammonium persulphate & $2 \cdot 5$ & pet & 1 \\
Nickel sulphate & $5 \cdot 0$ & pet & 22 \\
Formaldehyde & $1 \cdot 0$ & aq & 3 \\
Kathon CG & $0 \cdot 02$ & aq & 5 \\
Captan & $0 \cdot 5$ & pet & 6 \\
Hexachlorphene & $1 \cdot 0$ & pet & 1 \\
Parabens & $15 \cdot 0$ & pet & 2 \\
Balsam of Peru & $25 \cdot 0$ & pet & 1 \\
Fragrance mix & $8 \cdot 0$ & pet & 5 \\
Colophony & $20 \cdot 0$ & pet & 1 \\
Black rubber mix & $0 \cdot 6$ & pet & 1 \\
Mercapto mix & $2 \cdot 0$ & pet & 1 \\
Thiuram mix & $1 \cdot 0$ & pet & 0 \\
Carba mix & $3 \cdot 0$ & pet & 0 \\
\hline
\end{tabular}

Solvent was petroleum (pet) or water (aq).

Table 4 Association between job type, pierced ears, and patch test results

\begin{tabular}{|c|c|c|c|c|c|}
\hline & \multicolumn{2}{|c|}{ fob type $(n(\%))^{\star}$} & \multicolumn{2}{|c|}{ Pierced ears $(n(\%)) \dagger$} & \multirow[b]{2}{*}{ Total } \\
\hline & Apprentices & Stylists & - & + & \\
\hline $\begin{array}{c}\text { Sensiti } \\
- \\
+\end{array}$ & $\begin{array}{l}\text { lickel: } \\
48(77 \cdot 4) \\
14(22 \cdot 6)\end{array}$ & $\begin{array}{r}28(77 \cdot 8) \\
8(22 \cdot 2)\end{array}$ & $\begin{array}{r}49(89 \cdot 1) \\
6(10.9)\end{array}$ & $\begin{array}{l}27(62 \cdot 8) \\
16(37 \cdot 2)\end{array}$ & $\begin{array}{l}76 \\
22\end{array}$ \\
\hline $\begin{array}{c}\text { Sensiti } \\
- \\
+\end{array}$ & $\begin{array}{l}\text { n-nickel alle } \\
45(72 \cdot 6) \\
17(27 \cdot 4)\end{array}$ & $\begin{array}{l}26(72 \cdot 2) \\
10(27 \cdot 8)\end{array}$ & $\begin{array}{l}39(70 \cdot 9) \\
16(29 \cdot 1)\end{array}$ & $\begin{array}{l}32(74 \cdot 4) \\
11(25 \cdot 6)\end{array}$ & $\begin{array}{l}71 \\
27\end{array}$ \\
\hline Total & 62 & 36 & 55 & 43 & 98 \\
\hline
\end{tabular}

*Apprentices and stylists had essentially the same results in sensitivity to nickel $(P=0.97)$ and sensitivity to non-nickel allergen $(P=0.93)$.

†Those with pierced ears had a higher prevalence of sensitivity to nickel $(P=0.002)$ but not to non-nickel test agents $(P=0 \cdot 70)$. stylists $(P<0.0001)$. The prevalence of skin sensitivity to the patch agents was similar in hairdressers with MP type dermatitis and those with no dermatitis. All of those with eczema of the fingers, however, had skin sensitivity to at least one test agent. The MP type skin lesions were associated with time per week spent shampooing, but eczema of the fingers was not.

Of the 98 cases, 13 had either atopic dermatitis, allergic rhinitis or asthma, and were considered to be atopic. Of the 13 atopic hairdressers, $10(76.9 \%)$ had MP type dermatitis and two $(15 \cdot 4 \%)$ had eczema of the fingers. Of the non-atopic hairdressers, $58.2 \%$ had MP dermatitis and $22 \cdot 8 \%$ had eczema of the fingers. Severity of dermatitis, MP dermatitis, and eczema were not significantly different between atopic and non-atopic hairdressers.

\section{Discussion}

In this cross sectional study we found a high prevalence of hand dermatoses in hairdressers in Tainan City. The prevalence was higher among apprentices than stylists. When dermatitis was categorised into the MP joint pattern and eczema of the fingers, more apprentices $(69 \cdot 4 \%)$ than stylists $(36 \cdot 1 \%)$ had MP type dermatitis ( $P=0.0007)$; but similar proportions of apprentices $(22.6 \%)$ and stylists $(16 \cdot 7 \%)$ had eczema of fingers $(P=0.46)$. The MP type dermatitis was associated with longer hours of shampooing and might have been caused by chronic irritation to the skin of the MP area and infrequent use of protective gloves (table 1). An allergic aetiology was strongly implicated in the hairdressers with eczema of the fingers because positive patch tests were consistently found, although subjects with skin sensitivity to the patch test agents also presented with no skin problems or MP type dermatitis. Whether MP type dermatitis could be caused by contact with skin allergens remains unknown. It was conceivable, however, that some subjects with both MP type dermatitis and positive skin tests were caused by irritation rather than sensitisation.

In this investigation, we did not find the inflamed interdigital papules in the finger webs of hairdressers secondary to handling hair. Eighty one per cent of our stylists, however, were found to have scissors induced scars or wounds at the web between the index and middle fingers of the non-dominant hand. This was a unique manifestation that had not been described previously, and was caused by the common practice of holding the hair in the non-dominant hand between the second and third fingers and cutting it with the scissors in the dominant hand.

The common allergens reported among hairdressers include nickel, ${ }^{4} p$-phenylenediamine, ${ }^{58}$ glyceryl monothioglycolate, ${ }^{9}$ shampoo preservatives such as formaldehyde, ${ }^{1}$ ammonium thioglycolate, ${ }^{10}$ and rubber additives. $^{3}$ In this study, 43/98 hairdressers had positive reactions to one or more allergens. The prevalence of allergic reactions to the test 
agents was not different between the apprentices and the stylists (table 4). The common allergens in our subjects were nickel $(22 \%)$, Captan (6\%), Kathon CG (5\%), and fragrance $\operatorname{mix}(5 \%)$. The prevalence of sensitivity to nickel in hairdressers varied much, from $8-67 \%$ in different centers, and was dependent on the population studied. ${ }^{11}$ We found that similar to a previous finding pierced ears was a major risk factor for nickel sensitivity. ${ }^{12}$

Kathon CG and Captan were also important allergens in our study. Little information is available about their sensitivity rates among hairdressers. Captan was used in the past in shampoos. It was banned as a pesticide because of carcinogenicity. Its current use as a shampoo additive in Taiwan is unknown. Further investigation to elucidate the cause of this sensitivity is warranted. Kathon CG was introduced in 1977 as a biocide. It is used in industry and also cosmetics. Studies from several contact dermatitis clinics in Europe ${ }^{1314}$ showed a sensitivity rate of Kathon CG varying from $1 \cdot 1-6 \cdot 1 \%$. The highest of these rates might reflect large amounts of Kathon CG used in some countries. ${ }^{15}$

Five of our hairdressers were reactive to fragrance mix. These results were not different from previous reports. The sensitivity rate to formaldehyde, a preservative in many shampoos, was also similar to a previous report.'

Taiwanese people dye their hair less frequently, as reflected by a short exposure time in our subjects to hair dyes (8 min/week on average for stylists and 26 for apprentices). Only $3 / 98$ in this group of hairdressers were sensitive to $p$-phenylenediamine, a primary intermediate in hair dyes, and none was sensitive to either of the $p$-phenylenediamine derivatives ( $p$-toluenediamine sulphate or $p$-aminodiphenylamine) compared with $15 \%$, $8 \%$, and $4 \%$ in an European series. ${ }^{16}$ The rate of sensitivity to another component of hair dyes, 3-aminophenol, was also low compared with $3 \cdot 1-25 \%$ in previous studies. ${ }^{1}$

Sensitivity rates to rubber additives, black rubber mix (1/98), mercapto mix (1/98), carba mix (0/98), and thiuram mix (0/98) were very low. This could be attributed to the uncommon use of gloves at work in our subjects (table 2). Glyceryl monothioglycolate and ammonium thioglycolate, the permanent waving ingredients, caused quite variable rates of sensitivity among hairdressers. ${ }^{141017}$ Our subjects had low rates of sensitivity to these two chemicals.

Atopic subjects are more prone to developing irritant contact dermatitis. ${ }^{18}$ In this investigation, atopic subjects had a non-significant higher percentage of MP type dermatitis.

It is possible that those workers who were most sensitive to irritants or allergens in hairdressing tended to leave the occupation earlier, and we only saw the healthier hairdressers. In those with more severe dermatitis, the average work duration was shorter. There were few hairdressers with moderate or severe dermatitis who worked for
$>4$ years in this group. We therefore might have underestimated the overall prevalence and severity of skin diseases in hairdressers in this investigation. Further investigation with prospective follow up is important to determine the risk of developing dermatitis or sensitivity in hairdressers.

\section{Conclusion}

The present study of 98 hairdressers in Tainan showed a high incidence $(95 \%)$ of occupational hand dermatoses. Three patterns of skin problems were found: MP pattern dermatitis, eczema of the fingers, and scissor induced trauma. MP pattern dermatitis was found mainly in the apprentices. They had dry, lichenification, and scaling over the metacarpophalangeal joint associated with time of shampooing. Eczema of the fingers was found in the stylists and apprentices and was associated with sensitivity to the common allergens. The patch test results were different from previous reports in that the most common allergens were nickel, Captan, Kathon CG, and fragrance mix, and that the rates of sensitivity to hair dye and permanent wave ingredients were low.

The Center for Occupational Health is sponsored jointly by National Cheng-Kung University Medical College and Department of Health, Taiwan, Republic of China. We express our sincere thanks to Dr Jenny Su for her assistance in proofreading this manuscript.

1 Holness DL, Nethercott JR. Dermatitis in hairdressers Dermatol Clin 1990;8:119-26.

2 Cronin E, Kullavanijaya P. Hand dermatitis in hairdressers. Acta Derm Venereol (Stockh) 1979;59:(suppl 85):47-50.

3 Nethercott JR, MacPherson $M$, Choi BCK, Nixon P. Contact dermatitis in hairdressers. Contact Dermatitis 1986;14:73-9.

4 Lynde CD, Mitchell JC. Patch test results in 66 hairdressers. 1973-1981. Contact Dermatitis 1982;8:302-7.

5 Guerra L, Tosti A, Bardazzi F, Pigatto P, Lisi P, Santucci $\mathrm{B}$, et al. Contact dermatitis in hairdressers: the Italian experience. Contact Dermatitis 1992;26:101-7.

6 Cronin E. Dermatitis of the hands in beauticians. In Maibach HI, ed. Occupational and industrial dermatology, 2nd ed. Chicago: Year Book Medical Publishers. 1987 267-70.

7 Hannuksela M. Epicutaneous testing. Allergy 1979;34 5-10.

8 Fisher AA. Contact dermatitis. 3rd ed. Philadelphia: Lea and Febiger. 1986:389-90.

9 Storrs F. Permanent wave contact dermatitis: contact allergy to glyceryl monothioglycolate. $\mathcal{F} A m$ Acad Dermatol 1984;11:74-85.

10 Matsunaga $\mathrm{K}$, Hosokawa $\mathrm{K}$, Suzuki $\mathrm{M}$, Arima $\mathrm{Y}$ Hayakawa $R$. Occupational allergic contact dermatitis in beauticians. Contact Dermatitis 1988;18:94-6.

11 Burrows D, Adams RM. Metals. In: Adams RM, ed. Occupational skin disease. Philadelphia: WB Saunders, 1990:372-7.

12 Larsson-Stymne B, Widstrom L. Ear piercing-a cause of nickel allergy in schoolgirls. Contact Dermatitis 1985;13. 289-93.

13 Shuster S, Spiro J. Measurement of sensitization and its application to Kathon. Contact Dermatitis 1987;17: 299-302.

14 Tosti A, Manuzzi P, De Padova MP. Contact dermatitis to Kathon CG. Contact Dermatitis 1986;14:326-7.

15 De Groot AC, Weyland JW. Kathon CG: a review. F Am Acad Dermatol 1988;18:350-8.

16 Frosch PJ, Burrows D, Camarasa JG, Dooms-Goossens A Ducombs G, Lahti A, et al. Allergic reactions to a hairDucombs G, Lahti A, et al. Allergic reactions to a hairdressers' series: results from

17 Wahlberg JE. Nickel allergy and atopy in hairdressers. Contact Dermatitis 1975;1:161-5.

18 Rystedt I. Work-related hand eczema in atopics. Contact Dermatitis 1985;12:164-71. 